\section{PENGAMBILAN KEPUTUSAN STRATEGIS JENDELA ALAM LEMBANG: PERSPEKTIF KEUANGAN DAN STRATEGI}

\author{
Jacinta Winarto', Benny B.
} Tjandrasa' ${ }^{1}$ Lina Anatan ${ }^{*}$, Andre Sunjaya ${ }^{2}$, Novan Ardianto'

1) Magister Manajemen, Universitas Kristen Maranatha

2) Manajemen, Universitas Kristen Maranatha

\section{Article history \\ Received : 11-10-2019 \\ Revised : 11-02-2020 \\ Accepted : 30-03-2020}

\section{*Corresponding author}

Lina Anatan

Email : lina.anatan@yahoo.com

\begin{abstract}
Abstraksi
Sebagai organisasi yang bergerak dalam bidang wisata edukasi, Jendela Alam Lembang dihadapkan pada tantangan untuk dapat bersaing dengan wisatawisata lain yang tentunya masing-masing memiliki keunikan untuk ditawarkan kepada pengunjung. Hal ini mengakibatkan dalam beberapa periode, tingkat kunjungan wisatawan ke Jendela Alam Lembang mengalami penurunan yang cukup signifikan. Kegiatan pengabdian kepada masyarakat (abdimas) ini dilakukan dengan tujuan untuk mencari solusi atas permasalahan yang dihadapi Jendela Alam, yaitu penurunan jumlah pengunjung dan meningkatkan pendapatan kedai Jendela Alam melalui keputusan strategis yang tepat sasaran dan terarah. Untuk itu tim dosen dan mahasiswa gabungan dari Program Studi Magister Manajemen dan Program Studi S1 Manajemen bekerja sama untuk melaksanakan pengabdian masyarakat dengan judul "Pengambilan Keputusan Strategis Jendela Alam Lembang: Perspektif Keuangan dan Strategi." Adapun metode pelaksanaan yang dilakukan untuk pemecahan masalah yang dihadapi organisasi meliputi: Pemaparan materi terkait peramalan, capital budgeting, dan strategi bisnis serta usulan strategi baru melalui pembuatan keputusan strategis organisasi. Secara teknis, dalam penggalian informasi terkait permasalahan yang dihadapi Jendela Alam, tim abdimas melakukan observasi dan wawancara dengan pemilik dan karyawan Jendela Alam. Adapun hasil dan kesimpulan yang dicapai dalam kegiatan abdimas ini meliputi: 1) Pemilik dan karyawan memahami pentingnya proyeksi dengan menggunakan metode peramalan, 2) Peningkatan pendapatan kedai Jendela Alam melalui penerapan strategi STP (Segmenting, Targeting, Positioning) dan 7 P (Product, Price, Place, Promotion, People, Physical Evidence, dan Process).
\end{abstract}

Kata Kunci: Capital Budgeting, Pengambilan Keputusan Strategis, Peramalan

\begin{abstract}
As an organization that engaged in the field of educational tourism, Jendela Alam Lembang is faced with the challenge of being able to compete with other tourism in the surrounding area, which is certainly not small, and each has its uniqueness to offer to their visitors. This has resulted in a significantly decreased in the number of tourist arrivals to Jendela Alam Lembang in recent periods. This community service activity was conducted to find solutions to the main problems faced by Jendela Alam, the decreasing number of visitors, to increase the revenue of Jendela Alam's restaurant through strategic decisions that are targeted and directed. For this reason, the joint team of lecturers and students from the Master of Management Study Program and the S1 Management Study Program work together to carry out community service entitled "Strategic Decision Making in Jendela Alam Lembang: Financial and Strategic Perspectives." The implementation of methods is carried out for solving problems faced by the organization include: Presentation of materials related to forecasting, capital budgeting, and business strategies as well as new strategy proposed through organizational strategic decision making. Technically, in extracting information related to problems faced by Jendela Alam, the team conducted observations and interviews with Jendela Alam owners and employees. The results and conclusions reached in this community service activity include: 1) Owners and employees understand the importance of projections using forecasting methods, 2) Increasing the income of Jendela Alam Lembang through the application of the STP strategy (Segmenting, Targeting, and Positioning) and $7 \mathrm{P}$ (Product, Price, Place, Promotion, People, Physical Evidence, and Process).
\end{abstract}

Keywords: Capital Budgeting, Forecasting, Strategic Decision Making 


\section{PENDAHULUAN}

Literatur konseptual manajemen strategi mengemukakan bahwa kunci keberhasilan suatu organisasi untuk dapat bertahan dalam persaingan bisnis dan kondisi lingkungan organisasi yang ada adalah implementasi strategi organisasi dan pembuatan keputusan organisasi yang tepat dalam merespon kondisi lingkungan bisnis yang sedang dihadapi oleh organisasi. Manajemen strategi didefinisikan sebagai analisis, keputusan, dan tindakan yang dilakukan suatu organisasi untuk menciptakan dan mempertahankan keunggulan kompetitif sehingga mampu bertahan hidup dalam kondisi persaingan bisnis yang sangat dinamis dan tidak dapat diprediksi (Anatan, 2018). Definisi manajemen strategi tersebut menunjukkan elemen utama, yaitu: Pertama, berkaitan dengan proses dalam organisasi yang mencakup analisis, keputusan, dan tindakan yang dilakukan untuk merespon kondisi yang dihadapi organisasi, baik internal maupun eksternal; Kedua, manajemen strategi merupakan suatu studi tentang mengapa suatu organisasi mampu mengalahkan organisasi lain dalam suatu persaingan bisnis. Seperti dikemukakan sebelumnya, strategi organisasi dan pembuatan keputusan organisasi yang tepat menjadi kunci keberhasilan suatu organisasi untuk dapat bertahan dalam persaingan bisnis dan menghadapi dinamika kondisi lingkungan bisnis yang ada.

Strategi organisasi didefinisikan sebagai suatu perencanaan yang terintegrasi dan secara statistik dapat diverifikasi yang menekankan pada konsep tujuan, alokasi sumber daya, dan perencanaan untuk mencapai keselarasan antara lingkungan eksternal dan struktur dan proses internal. Strategi organisasi diformulasikan melalui suatu proses pembuatan keputusan yang didukung oleh riset produktif untuk mempelajari bagaimana organisasi membuat keputusan strategis baik secara individual maupun berdasarkan keputusan bersama. Proses pembuatan keputusan strategis dalam suatu organisasi merupakan hal yang penting karena berkaitan dengan tindakan yang diambil dan sumber daya yang dilibatkan sebagai satu kesatuan dalam menghasilkan keputusan yang tepat sesuai situasi dan kondisi yang sedang dihadapi organisasi. Outcome dari proses pembuatan keputusan, sangat tergantung pada pembuat keputusan, khususnya upper-level management dengan tanpa mengabaikan kepentingan para stakeholders yang terlibat dalam organisasi dan kemungkinankemungkinan yang akan dihadapi oleh organisasi di masa yang akan datang (Mintzberg, 1975). Dalam pembuatan keputusan strategis juga perlu mempertimbangkan segala aspek yang terkait dengan public interest, khususnya dalam kondisi krisis seperti penurunan kinerja organisasi yang telah terjadi selama periode tertentu, dengan mempertimbangkan apakah krisis atau penurunan kinerja tersebut diakibatkan oleh faktor eksternal atav internal organisasi (Sommer \& Pearson, 2007; Gudono \& Anatan, 2015).

Pengabdian masyarakat (abdimas) yang melibatkan dosen-dosen dari Program Studi Magister Manajemen dan Program Studi Manajemen ini dilakukan sebagai sarana untuk berbagi pengetahuan kepada mitra kerjasama, yaitu Jendela Alam Lembang, terkait pentingnya pemahaman konsep, pengembangan strategi organisasi, dan pembuatan keputusan strategis khususnya dalam kondisi penurunan kinerja organisasi yang saat ini sedang dihadapi oleh organisasi dengan mempertimbangkan peramalan kondisi organisasi pada masa yang akan datang. Kegiatan berbagi pengetahuan dari akademisi ke mitra kerja sangat penting dilakukan sebagai wujud kontribusi akademisi dalam memberikan akses pengetahuan spesifik yang mungkin sulit diperoleh oleh mitra kerjasama dalam internal organisasinya (Anatan, 2018) Pelaksanaan kegiatan pengabdian masyarakat di Jendela Alam Lembang diharapkan dapat memberikan kontribusi signifikan dalam penyelesaian permasalahan yang dihadapi melalui beberapa proses kegiatan berikut: Pemaparan materi terkait peramalan, capital budgeting, dan pembuatan keputusan strategis organisasi pada kondisi penurunan kinerja organisasi.

Pelaksanaan abdimas di Jendela Alam Lembang dengan judul "Pengambilan Keputusan Strategis Jendela Alam Lembang: Perspektif Keuangan dan Strategi" didasarkan pada kondisi atau permasalahan yang sedang dihadapi oleh Jendela Alam. Adapun masalah tersebut meliputi: 1) penurunan jumlah pengunjung yang signifikan, 2) penurunan jumlah pendapatan akibat penurunan jumlah pengunjung dan faktor musiman sehingga mengakibatkan pendapatan perusahaan tidak stabil, 3) Meningkatnya jumlah pesaing baik yang bergerak di industri serupa dalam bidang wisata edukasi, maupun pada industri yang berbeda, seperti makin menjamurnya kafe-kafe yang menawarkan layanan dan spot-spot yang instagramable, 4) Pada bagian kedai, menunjukkan masih minimnya pengunjung yang tertarik mengunjungi dan berbelanja di Kedai Jendela Alam, diduga akibat lokasi restoran tidak mudah dijangkau pengunjung.

Secara umum, pelaksanaan pengabdian masyarakat di Jendela Alam Lembang bertujuan untuk memberikan kemanfaatan, khususnya dalam hal memberikan pengetahuan kepada mitra 
kerjasama terkait pentingnya pemahaman konsep, pengembangan strategi organisasi, dan pembuatan keputusan strategis khususnya dalam kondisi penurunan kinerja organisasi dengan mempertimbangkan peramalan kondisi organisasi pada masa yang akan datang. Bagi akademisi, kegiatan abdimas ini diharapkan dapat memotivasi para dosen untuk meningkatkan minat dan kepedulian terhadap masyarakat sekitar dengan melakukan kegiatan yang bermanfaat tidak hanya bagi pengembangan ilmu sesuai bidang keahlian dosen, tetapi juga berperan penting dalam pengembangan jenjang karir dosen dan secara spesifik sebagai wujud kontribusi akademisi terhadap lingkungan sekitar.

Secara khusus, kegiatan pengabdian masyarakat yang dilakukan di Jendela Alam Lembang diharapkan dapat memberikan manfaat tidak hanya bagi dosen pelaksana, mitra pengabdian masyarakat, tetapi juga bagi Universitas Kristen Maranatha Bandung. Adapun manfaat yang diharapkan adalah sebagai berikut: Pertama, bagi dosen kegiatan pengabdian kepada masyarakat dapat digunakan sebagai media dalam melaksanakan salah satu kewajiban Tri Dharma Perguruan Tinggi, yaitu pengabdian masyarakat secara efektif dengan cara membagikan ilmu pengetahuan yang dimiliki sesuai dengan bidang keahlian masing-masing untuk membantu penyelesaian permasalahan yang dihadapi oleh mitra perguruan tinggi. Kedua, bagi mitra universitas, kegiatan pengabdian masyarakat yang dilakukan diharapkan dapat memberikan kontribusi dalam menyelesaikan permasalahan yang dihadapi oleh organisasi. Ketiga, bagi Universitas Kristen Maranatha, kegiatan pengabdian kepada masyarakat merupakan wujud kontribusi peran universitas sebagai pendidikan tinggi terhadap pengembangan kerjasama kemitraan dengan industri dan masyarakat.

Adapun kendala utama yang dihadapi tim dalam persiapan pelaksanaan kegiatan pengabdian kepada masyarakat di Jendela Alam adalah lamanya pembuatan PKS oleh Direktorat Kerjasama yang disebabkan padatnya kegiatan mereka sehingga kegiatan abdimas yang tadinya dijadwalkan Februari menjadi mundur dari jadwal semula. Untuk pelaksanaannya, ada permintaan dari pemilik agar ditambahkan pembahasan lebih mendalam mengenai kedai yang ada di Jendela Alam.

\section{METODE PELAKSANAAN}

Kegiatan pengabdian masyarakat dilaksanakan selama dua hari yaitu tanggal 21 dan 22 Maret 2019.
Hari pertama pemaparan materi dilakukan oleh Dr. Benny B. Tjandrasa, S.E., M.M. (topik peramalan), Dr. Lina Anatan, S.E., M.Si. (topik pengambilan keputusan strategis dan Dr. Jacinta Winarto, S.E., M.T. (topik capital budgeting). Hari kedua diisi dengan acara pelatihan yang bertujuan untuk mengaplikasikan materi peramalan yang dipandu oleh Dr. Benny B. Tjandrasa, S.E., M.M. Peserta mencoba mempraktekkan materi yang sudah dipaparkan. Berikut dibahas secara lebih rinci kegiatan yang dilakukan pada masing-masing sesi dalam kegiatan pengabdian masyarakat.

\section{PEMBAHASAN \\ Hari I Sesi I : Peramalan Untuk Bisnis (Dr. Benny B. Tjandrasa, S.E., M.M)}

Pada sesi ini dibahas teknik-teknik untuk membuat perkiraan-perkiraan yang diharapkan dapat membantu proses pengambilan keputusan. Terdapat dua kelompok teknik, yaitu: metode kuantitatif dan kualitatif. Peramalan Kualitatif digunakan untuk meramalkan permintaan secara kualitatif, biasanya dilakukan dengan survei terhadap keinginan dan ekspektasi calon pembeli akan produk yang dibutuhkannya dimasa yang akan datang. Cara ini dilakukan dengan sampel dan kuesioner, yaitu mencatat sikap dari calon pembeli (perubahan dari quantity demanded) apabila diadakan perubahan terhadap harga barang, pemberian sistem kredit, iklan, dsb. Selain meramalkan dengan cara survey, dapat pula dilakukan dengan cara "opinion pools" yang terdiri dari pooling para executive, pooling para Salesforce, dan pooling keinginan konsumen. Adapun pendekatan riset pemasaran untuk mengestimasi permintaan meliputi: 1) Consumer Clinic, yaitu dengan melakukan eksperimen dan simulasi (di dalam suatu laboratorium), yaitu melihat perubahan yang terjadi pada dependent variable (quantity demanded) akibat perubahan pada independent variable, 2) Market Experiment, cara ini sama dengan consumer clinic, namun eksperimen dilakukan di pasar yang sesungguhnya.

Peramalan Kuantitatif, menjelaskan berbagai metode peramalan kuantitatif, diantaranya adalah (Makridakis et al., 2009): metode simple moving average, metode double moving average, metode simple exponential smoothing, metode double exponential smoothing, metode regression analysis. Dari berbagai metode tersebut, cara yang paling baik untuk melakukan peramalan terhadap permintaan adalah dengan regression analysis. Analisis regresi merupakan analisis yang digunakan untuk menganalisis satu variabel terikat $(Y)$ dengan menggunakan satu variabel bebas $(X)$. Variabel bebas yang dipilih adalah yang mempunyai hubungan (korelasi) dengan variabel terikat. Untuk 
peramalan penjualan berdasarkan waktu, maka variabel bebasnya biasa dinotasikan sebagai $t$, sehingga metode ini memiliki nama lain yaitu time series analysis. Dalam time series analysis, pada umumnya penyebab dari fluktuasi dalam time-series data adalah: 1) Secular trend / trend projection: yaitu merupakan trend jangka panjang yang merupakan perpanjangan dari trend masa lalu. 2) Cyclical fluctuations, yang merupakan gambaran dari keadaan ekonomi jangka panjang. 3) Seasonal variation, yaitu fluktuasi yang disebabkan oleh musim. Pengaruh-pengaruh irregular dan random yang unik untuk tiap-tiap perusahaan. Secara sederhana dianggap bahwa kejadian masa lalu akan terjadi lagi dimasa yang akan datang. Kejadian masa lalu biasanya dinyatakan dalam suatu regression line:

$$
\mathrm{St}=\mathrm{SO}+\mathrm{bt}
$$

yang diturunkan dari rumus persamaan

$$
Y=a+b . \dagger
$$

Gambar 1 menunjukkan beberapa foto kegiatan pemaparan materi dan diskusi pada hari pertama sesi kesatu tentang peramalan untuk bisnis.

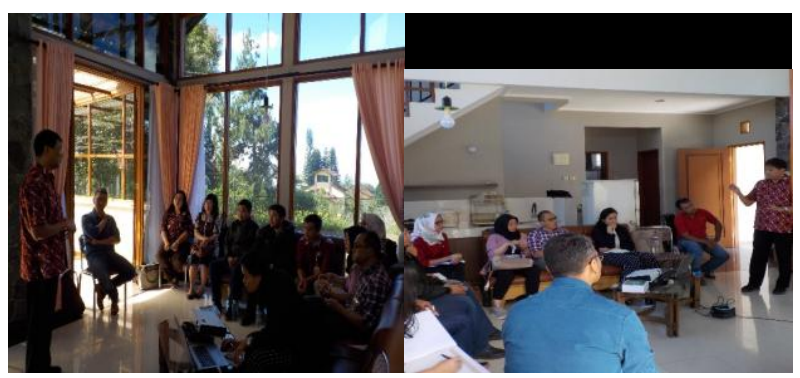

Gambar 1. Sesi Peramalan Untuk Bisnis

Hari I Sesi II: Pengambilan Keputusan Strategis (Dr. Lina Anatan, S.E., M.Si.)

Pada sesi ini membahas tiga masalah utama terkait proses manajemen strategi, hubungan manajemen strategi dengan keputusan strategi dan pengambilan keputusan perusahaan. Proses manajemen strategi memiliki makna bagaimana suatu organisasi mendefinisikan strategi-nya dan juga proses yang dilakukan oleh manajer dalam membuat pilihan dari serangkaian strategi untuk mencapai kinerja yang lebih baik. Gambar 2 menunjukkan Proses Manajemen Strategi. Proses manajemen strategi dibagi dalam tiga tahapan yang meliputi perumusan dan perencanaan strategi, pelaksanaan strategi, dan evaluasi serta pengawasan (Abel, 2009; Prawirosentono\& Primasari, 2016). Tahap awal yang harus dilakukan dalam menentukan proses manajemen strategi adalah melakukan scanning lingkungan, baik lingkungan internal maupun lingkungan eksternal perusahaan.

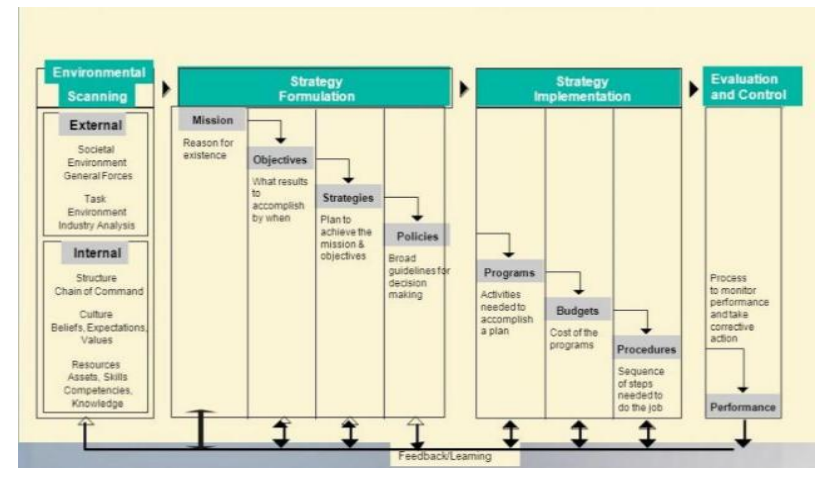

Gambar 1. Strategic Management Process Sumber: Wheelen \& Hunger (2010) dalam Anatan (2018)

Bagaimana hubungan manajemen strategi dengan bidang fungsional lain seperti manajemen keuangan, manajemen pemasaran, manajemen sumber daya manusia, dan manajemen operasional? Pada dasarnya setiap manajemen fungsional tersebut didalamnya sudah mengandung unsur strategi. Sebagai contoh, dalam manajemen keuangan terdapat pendekatan-pendekatan strategis untuk mencari modal dengan biaya rendah misalnya IRR, Payback Period, dan lain sebagainya. Dalam manajemen pemasaran dikenal marketing mix, strategi penjualan, dan lain sebagainya.

Dalam hal pengambilan keputusan korporasi, seorang pimpinan perusahaan dihadapkan pada berbagai situasi dalam pengambilan keputusan, sehingga pengambil keputusan harus mengetahui klasifikasi kondisi saat pengambilan keputusan (David \& Montgomery, 2009; Campbell \& Alexander, 2005). Adapun klasifikasi kondisi pengambilan keputusan digolongkan dalam tiga kondisi yaitu (Thomas, 1984; Deal \& Allan, 2007): 1) Keputusan Kondisi Pasti, yaitu kondisi dimana faktor-faktor yang mempengaruhi diketahui secara pasti. 2) Keputusan Kondisi Tak Pasti, yaitu kondisi dimana banyak faktor atau informasi yang mempengaruhi keputusan tersebut tidak diketahui secara pasti, 3) Keputusan Beresiko, dimana pengambil keputusan dihadapkan pada kondisi beresiko. Hal utama yang harus dipertimbangkan adalah mengukur peluang dari setiap alternatif keputusan yang akan diambil. Gambar 3 menunjukkan beberapa foto kegiatan pemaparan materi dan diskusi pada hari pertama sesi kedua tentang pengambilan keputusan strategis. 


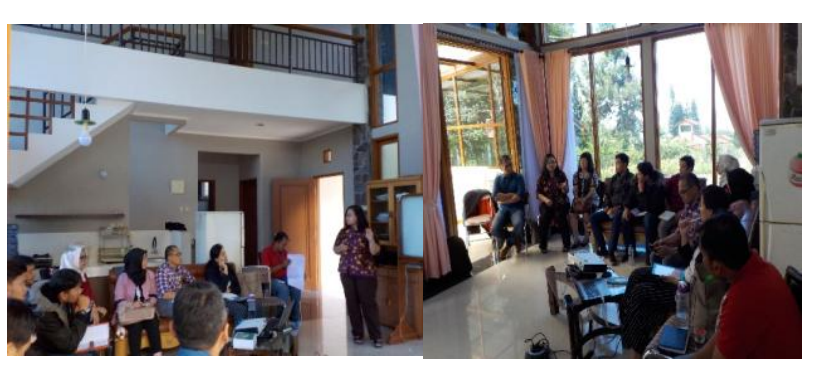

Gambar 3. Sesi Pengambilan Keputusan Strategis

Hari I Sesi III: Capital Budgeting dan Strategi 7 P (Dr. Jacinta Winarto, S.E., M.T.)

Pada sesi ini dibahas mengenai capital budgeting yang mempunyai arti sangat penting bagi perusahaan karena lamanya pengembalian dana. Kebutuhan dana harus diperhitungkan secara tepat. Dilihat dari segi ruang lingkup usahanya, investasi dapat dibagi dua, yaitu investasi pada aktiva nyata dan aktiva keuangan. Investasi dapat dikategorikan dalam: 1) Replacement, yaitu aset-aset yang sudah tua perlu diganti dengan aset-aset yang baru, 2) Expantion, yaitu penambahan jumlah aset atau pembukaan pabrik baru, 3) New product activities, yaitu investasi di bidang usaha baru yang berbeda dengan usaha sebelumnya, 4) Others, yaitu Investasi air conditioner, pemasangan sistem musik. Selanjutnya, menurut Sartono (2014), ada dua komponen utama aliran kas yaitu initial cash flow dan operational cash flow. Initial cash flow merupakan pengeluaran investasi. Pengeluaran ini mencakup pengeluaran yang diperlukan mulai saat timbul ide atau gagasan untuk beroperasi sampai perusahaan siap beroperasi. Yang kedua adalah operational cash flow, yang berkaitan dengan kas masuk (penerimaan kas) dan kas keluar (pengeluaran kas) selama periode perusahaan melakukan aktivitas usaha (beroperasi). Operational cash flow ini akan mempunyai aliran kas bersih, dimana diharapkan nilainya positif sehingga perusahaan mendapatkan pengembalian atas investasi yang dilakukan. Pemilik memerlukan masukan mengenai kondisi kedai yang ada di Jendela Alam. Sebelum ditentukan apakah kedai di Jendela Alam ini perlu dilakukan restorasi yang dapat dikategorikan expantion, maka perusahaan perlu memperhatikan segmenting, targeting, dan positioning (STP) serta product, price, place, promotion (Kotler \& Keller, 2009), people, physical evidence, process (7 P).

\section{Segmentasi Pasar}

Sekelompok pelanggan yang memiliki sekumpulan kebutuhan (mengenai edukasi alam) dan keinginan yang serupa. Tugas pemasar adalah mengidentifikasi segmen dan memutuskan segmen mana yang akan dibidik. Segmen untuk kedai di PT Jendela Alam adalah sekolah dan keluarga

\section{Target Pasar}

Setelah perusahaan mengidentifikasi peluang segmen pasarnya, perusahaan harus memutuskan berapa banyak dan segmen pasar mana yang akan dibidik. Pemasar mulai menggabungkan beberapa variabel dalam usahanya mengidentifikasi kelompok sasaran yang lebih kecil dan didefinisikan dengan lebih baik.

Target untuk kedai di PT Jendela Alam adalah:

- Anak-anak sekolah Kelompok Bermain, TK A, TK B, SD

- Keluarga dengan anak berusia maksimum SD

- Ibu-ibu yang mengantar

\section{Positioning}

Untuk setiap segmen, perlu diciptakan proposisi nilai dan strategi positioning harga-produk berdasarkan kebutuhan dan karakteristik unik pelanggan segmen tersebut. Kedai Jendela Alam telah memposisikan dirinya untuk menawarkan hidangan dengan:

- Harga yang terjangkau

- Kualitas, gizi, serta tampilan hidangan yang menarik

- Lingkungan restoran adalah pemandangan alam dan udara yang segar

\section{P (Product, Price, Place, Promotion, People, Physical Evidence, dan Process)}

7 P merupakan suatu pendekatan dalam memasarkan produk dan jasa yang dilakukan suatu perusahaan. Definisi lainnya, suatu strategi penjualan yang dirancang untuk menghasilkan pertukaran yang saling menguntungkan untuk pasar yang dituju, biasanya dikenal sebagai marketing mix yang terdiri dari: Product, Price, Place, Promotion, People, Physical Evidence, dan Process.

\section{Product (Produk)}

Perusahaan dapat memperhatikan berbagai hal yang berhubungan dengan produk, seperti ragam produk, kualitas, desain, fitur, nama merek, kemasan, ukuran, layanan, jaminan, dan pengembalian. Dalam hal ini Kedai Jendela Alam telah menyediakan berbagai menu, snack, dan minuman yang berkualitas terdiri dari: menu utama, menu tambahan, menu sayur, snack/cemilan, minuman bergizi (Jus), minuman lainnya, dan es krim.

\section{Place (Tempat)}

Place (tempat) disini meliputi saluran, cakupan, pilihan, lokasi, persediaan dan transportasi. Lokasi Kedai Jendela Alam sudah cukup baik karena berlokasi agak di depan pintu masuk akan tetapi kurang terlihat karena tersamar dengan banyak 
tanaman di depannya. Agar terlihat diusulkan untuk menggunakan spanduk, tanda panah,atau billboard kedai yang lebih mencolok (eye catching). Untuk jangka panjang disarankan agar area kedai mempunyai lebih dari satu pemandangan sehingga dapat menangkap suasana kebun/ alam lebih banyak.

\section{Promotion (Promosi)}

Promosi merupakan kegiatan mengkomunikasikan informasi dari penjual kepada konsumen atau pihak lain melalui saluran penjualan untuk mempengaruhi perilaku konsumen. Promosi dapat meliputi promosi penjualan, periklanan, tenaga penjualan, hubungan masyarakat, dan pemasaran langsung. Agar keberadaan Kedai Jendela Alam lebih banyak diketahui oleh masyarakat, maka dapat dicantumkan di papan denah yang ada di depan, dapat juga diberitakan melalui website Jendela Alam, dapat pula dibuatkan tulisan kedai yang eye catching sehingga terlihat dari berbagai sisi.

\section{People (Orang)}

People disini adalah karyawan penyedia jasa pelayanan maupun penjualan atau orang-orang yang terlibat secara langsung maupun tidak langsung dalam proses layanan itu sendiri. Kedai Jendela Alam mempunyai karyawan yang siap tanggap, ramah, dan kompeten dalam memasak.

\section{Process (Proses)}

Proses merupakan kegiatan pelayanan yang diberikan kepada konsumen selama melakukan pembelian produk atau jasa. Pengusaha melalui karyawannya dapat menawarkan berbagai macam bentuk pelayanan yang menarik konsumen. Disini Kedai Jendela Alam telah memberikan pelayanan dengan waktu tunggu dari pemesanan makanan sampai makanan tiba dengan waktu yang tidak terlalu lama serta proses pembuatan dan penataan makanan yang higienis.

\section{Physical Evidence (Lingkungan Fisik)}

Kondisi fisik di luar tempat usaha dan di dalam tempat usaha. Kondisi di luar tempat usaha seperti dekorasi luar, tampilan fisik luar, cuaca, kondisi geografis dan suasana lingkungan. Kondisi di dalam tempat usaha seperti dekorasi, bentuk atau ukuran ruangan, suara, aroma, cahaya, layout. Kedai Jendela Alam telah mempunyai kedai makan yang tertata rapi. Untuk kedepannya akan ditaruh beberapa tanaman obat dengan display kegunaannya di depan rumah makan, serta di dalam restoran akan dibuat desain interior dengan gambar-gambar yang menstimulasi anak-anak bermain sambil menunggu hidangan tiba. Gambar 4 menunjukkan beberapa foto kegiatan pemaparan materi dan diskusi pada hari pertama sesi ketiga tentang capital budgeting dan strategi 7P.

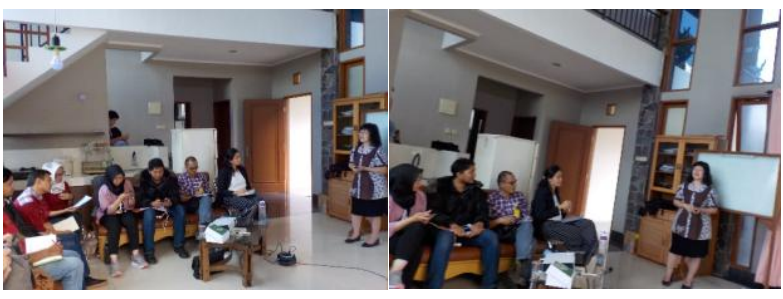

Gambar 4. Sesi Capital Budgeting dan Strategi 7P

Hari Kedua: Implementasi Metode Peramalan Dalam Bisnis (Dr. Benny B. Tjandrasa, S.E., M.M)

Seperti telah dibahas pada bagian metode pelaksanaan, hari kedua diisi dengan acara pelatihan yang bertujuan untuk mengaplikasikan materi peramalan yang dipandu oleh Bapak Benny B. Tjandrasa. Pada sesi ini, peserta mencoba mempraktekkan materi yang sudah dipaparkan yaitu mencari ramalan penjualan pada tahun 2018 musim ke 1,2,3 dan 4 (Gambar 5) dengan materi latihan soal yang digunakan oleh peserta kegiatan seperti tabel 1 .

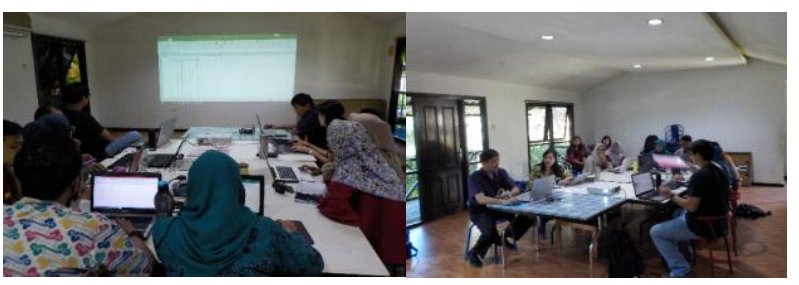

Gambar 5. Implementasi Metode Peramalan dalam Bisnis

Tabel 1. Materi latihan Soal Peramalan Penjualan

\begin{tabular}{ccc}
\hline Time Period & Quantity & $\operatorname{In} Q$ \\
\hline 2014.1 & 11 & 2.40 \\
2014.2 & 15 & 2.71 \\
2014.3 & 12 & 2.48 \\
2014.4 & 14 & 2.64 \\
2015.1 & 12 & 2.48 \\
2015.2 & 17 & 2.83 \\
2015.3 & 13 & 2.56 \\
2015.4 & 16 & 2.77 \\
2016.1 & 14 & 2.64 \\
2016.2 & 18 & 2.89 \\
2016.3 & 15 & 2.71 \\
2016.4 & 17 & 2.83 \\
2017.1 & 15 & 2.71 \\
2017.2 & 20 & 3.00 \\
2017.3 & 16 & 2.77 \\
2017.4 & 19 & 2.94 \\
\hline
\end{tabular}




\section{KESIMPULAN}

Secara keseluruhan, acara pengabdian kepada masyarakat yang dilakukan di Jendela Alam berjalan dengan baik. Jumlah peserta yang hadir di hari I adalah 12 orang, hari II menjadi 11 orang. Berdasarkan masukan yang diperoleh dalam proses evaluasi melalui pengisian google form dapat disimpulkan bahwa untuk tema seminar, ketepatan waktu, suasana dinyatakan baik. Sedangkan penggunaan alat bantu dinyatakan cukup. Tingkat respon peserta dalam memberikan pertanyaan dan masukan hanya kurang dari separuh jumlah peserta, dengan perkataan lain, beberapa peserta merupakan peserta yang pasif. Sebagai wujud tindak lanjut kegiatan abdimas ini, pada kegiatan yang akan datang abdimas akan memfokuskan pada pelatihan software sehingga organisasi bisa melakukan penelitian sendiri bila dibutuhkan, sebagai contoh adalah kebutuhan organisasi untuk melakukan survei kepuasan pelanggan, penilaian kinerja karyawan, maupun penilaian kerja organisasi. Selain itu, abdimas terkait pengenalan software untuk melakukan peramalan juga diperlukan agar organisasi dapat melakukan peramalan sendiri dimasa yang akan datang.

\section{DAFTAR PUSTAKA}

Abell, D., 2009. Starting point of strategic planning. New York: Engeewood Cliffs., N.J., Prentice Hall.

Anatan, L., 2018. An institutional perspective of knowledge transfer within university and industry alliance. International Journal of Economic Policy in Emerging Economies, 11 (4), 378-395.

Anatan, L., 2018. The use of Conjoint Analysis in Strategic Decision Making: An Initial Study. Kinerja, 22 (1), 45-68.

Campbel, G.M.A, \& Alexander, M., 2005. Corporate level strategy. New York USA: John Wiley \& Sons.

David, E.J., \& Montgomary, C.A., 2009. Corporate Strategy, New York, USA: Mc. Graw Hill, Irwin.

Deal, T.E., \& Allan, K., 2007. The rise and ritual of corporate life. USA: Mc.GrawHill.

Gudono, M., \& Anatan, L., 2015. The Financial Performance of International Takeovers of the State-owned Companies: Evidences from Indonesia after the 1997/1999 Asian Crisis. Universal Journal of Management 3(6): $211-221$

Makridakis, S., Wheelwright, S. C., \& Hyndman, R. J. (2009). Forecasting methods and applications. John wiley \& sons.

Mintzberg, H., 1975. The manager'sjob: Folklore and fact. Harvard Business Review, 53(4), 49-61.

Kotler, P. \& Keller, K.. 2014. Manajemen Pemasaran. Edisi 13 Jilid 1. Jakarta: Erlangga.

Prawirosentono, S., \& Primasari, D., 2016. Manajemen stratejik dan pengambilan keputusan korporasi. PT Bumi Aksara Jakarta

Sartono, A., 2014. Manajemen Keuangan - Teori dan Aplikasi. Edisi 4. Yogyakarta: BPFE UGM

Sommer, A., \& Pearson, C. M., 2007. Antecedents of creative decision making in organizational crisis: A team-based simulation. Technological Forecasting and Social Change: An International Journal, 74, 1234-1251.

Thomas, H., 1984. Strategic Decision Analysis: Applied Decision Analysis and its role in the strategic management process. Strategic Management Journal, $5,139-156$. 